\title{
Uso y verificación con indicadores biológicos en esterilizadores de cirujanos dentistas de San Luis Potosí, México
}

\author{
N uria Patiño-Marín, CD, MC, ${ }^{(1)}$ Juan Pablo Loyola-Rodríguez, CD, PhD, ${ }^{(2)}$ \\ Luis Fernando Tovar-Reyes, CD.(3)
}

Patiño-Marín N, Loyola-Rodríguez JP,Tovar-Reyes LF. Uso y verificación con indicadores biológicos en esterilizadores de cirujanos dentistas de San Luis Potosí, México.

Salud Publica Mex 2001;43:455-458. El texto completo en inglés de este artículo está disponible en: http://www.insp.mx/salud/index.html

\begin{abstract}
Resumen
Objetivo. Conocer el uso y verificar los ciclos de esterilización con indicadores biológicos en los equipos utilizados por cirujanos dentistas de la Facultad de Estomatología de la Universidad Autónoma de San Luis Potosí (UASLP) y del Colegio Dental Potosino. Material y métodos. Estudio transversal hecho en 1999-2000. El $65 \%(n=130)$ de los odontólogos participaron con un esterilizador, la verificación se realizó por indicadores que contenían esporas de Bacillus subtilis y de Bacillus stearothermophilus. Resultados. Participaron 30 autoclaves y 100 esterilizadores de calor seco, 23 de ellos (17.7\%) presentaron crecimiento bacteriano; el $16.1 \%(n=21)$ de los participantes utilizan los indicadores bioló gicos como verificador. Los dos métodos de esterilización presentaron crecimiento bacteriano con frecuencias similares $(p=>0.66)$. Conclusiones. Pocos cirujanos dentistas verifican su esterilizador con indicadores biológicos en los equipos que presentaron crecimiento bacteriano, sus fallas se encontraron en el proceso de esterilización. El texto completo en inglés de este artículo está disponible en: http://www.insp.mx/salud/index.html
\end{abstract}

Palabras clave: control de infecciones; esterilización; indicador biológico; México

\author{
Patiño-Marín N, Loyola-Rodríguez JP,Tovar-Reyes LF. \\ Verification and utilization \\ of sterilizing equipment by dentists \\ in San Luis Potosi, Mexico. \\ Salud Publica Mex 2001;43:455-458. \\ The English version of this paper \\ is available at: http://www.insp.mx/salud/index.html
}

\begin{abstract}
A bstract
Objective.To assess the utilization of sterilizing equipment used by dentists, and verification of sterilization using biological indicators. Material and methods A cross-sectional study was conducted in 1999-2000, among 130 (65\%) dentists having sterilizing equipment, at Facultad de Estomatología, Universidad Autónoma de San Luis Potosí and Colegio Dental Potosino. Biological indicators for sterilization containing Bacillus subtilis and Bacillus stearothermophilus were used. Results. Thirty autoclaves and 100 dry-heat sterilizers were evaluated: $23(17.7 \%)$ of them showed bacterial growth.Twenty-one (16.1\%) dentists already were using biological indicators to verify their sterilizing equipment. Both sterilization methods were found to allow bacterial growth with similar frequencies $(p=>0.66)$. Conclusions. Few dentists verify the quality of sterilization process through biological indicators; bacterial growth and failure of sterilization were evidenced. The English version of this paper is available at: http://www.insp.mx/salud/index.html
\end{abstract}

Key words: infection control; sterilization; biological indicators; Mexico

Trabajo financiado por el Sistema de Investigación Miguel Hidalgo (SIHGO) del Conacyt (33650-M), el FAI (Fondo de Apoyo a la Investigación) y FAD (Fondo de A poyo a la Docencia) de la UASLP.

(1) Profesor A sistente, Centro de Investigación, Maestría en Ciencias 0 dontológicas, Facultad de Estomatología, UASLP, México.

(2) Director del Centro de Investigación y de la Maestría en Ciencias 0 dontológicas, Facultad de Estomatología, UASLP, México.

(3) Pasante de Servicio Social en la Clínica de Medicina Estomatológica, Centro de Investigación, Facultad de Estomatología, UASLP, México.

Fecha de recibido: 30 de noviembre de 2000 • Fecha de aprobado: 5 de abril de 2001

Solicitud de sobretiros: Dr. Juan Pablo Loyola Rodríguez, Centro de Investigación, Maestría en Ciencias 0 dontológicas, Facultad de Estomatología, UASLP. Mariano Avila 295-2, colonia Tequisquiapam CP 78250, San Luis Potosí, S.L.P.Tel: (4) 82623 60, Fax (4) 8139743.

Correo electrónico: jloyola@ uaslp.mx 
$\mathrm{L}$ os Cirujanos Dentistas (CD) están expuestos a innumerables fuentes de posibles infecciones, como son: saliva, sangre, instrumentos, equipo contaminado etcétera, que pueden ser transmisores de microorganismos a pacientes y a personal odontológico. La Asociación Dental Americana (ADA) y la Norma Oficial Mexicana (NOM) para la Prevención y Control de Enfermedades Bucales, recomiendan medidas de protección para evitar la transmisión de enfermedades infecciosas, entre aquéllas se encuentra la esterilización de instrumentos. ${ }^{1,2}$ Algunos de los métodos de esterilización para uso odontológico son vapor a presión (autoclave) y calor seco; la temperatura recomendada para esterilizar instrumentos en autoclave es de $121^{\circ} \mathrm{C}, 1 \mathrm{Kg} / \mathrm{cm}^{2}$ durante 20 a 30 minutos, según las especificaciones del fabricante; el proceso de calor seco debe alcanzar una temperatura de $170{ }^{\circ} \mathrm{C}$ durante una hora para esterilizar instrumentos. ${ }^{2}$ La verificación de los ciclos de esterilización se puede hacer por indicadores químicos y biológicos (IB); sin embargo, los IB son el único método aceptado internacionalmente; es considerado el más confiable y seguro; su presentación es en ámpulas o tiras de papel embebidas de esporas bacterianas. ${ }^{3}$ Se recomienda que los equipos de esterilización deben ser verificados mensualmente por IB según la NOM, aunque algunos autores recomiendan aplicar los IB semanalmente. ${ }^{4} \mathrm{El}$ objetivo del estudio es conocer el uso y verificar con IB los ciclos de esterilización en los esterilizadores de CD de la Facultad de Estomatología de la Universidad Autónoma de San Luis Potosí (FE-UASLP) y el Colegio Dental Potosino (CDP).

\section{Material y métodos}

El estudio se realizó durante el periodo de marzo de 1999 a febrero de 2000, se invitó a participar a través de un programa de información sobre la verificación con IB a CD de la FE-UASLP y CDP con un total de 200 CD (80 de la FE-UASLP y 120 del CDP). Los criterios de inclusión para los participantes fueron CD adscritos a la FE-UASLP y al CDP que tuvieran esterilizadores de calor seco y/o autoclave y su aceptación verbal de verificar su equipo. Los criterios de exclusión: CD con equipo descompuesto que no puedan realizar el ciclo de esterilización. Criterios de eliminación: participantes que no entregaron el cuestionario contestados con todos sus datos. Los cuestionarios fueron entregados a los CD; la recolección de la información se basó en tipo de esterilización, condiciones del proceso (tiempo, temperatura y presión), tipo de verificación que se practica, personal encargado del procedimiento, conocimiento y utilización de los IB (sí o no). Se utilizaron IB en tiras (Bacterial Spore Sterilization Strip, Raven Biological Labs, USA) con esporas de Bacillus subtilis var. níger para los esterilizadores de calor seco y de Bacillus stearothermophilus para los autoclaves. Las muestras fueron marcadas con un número clave y entregadas al azar a cada uno de los participantes, después de recibir el cuestionario, para ser sometidas por el cirujano dentista a un ciclo de esterilización en su consultorio. Las muestras se entregaron al Centro de Investigación de la Facultad de Estomatología donde se procesaron. El medio utilizado para el crecimiento bacteriano fue Tripticasa de soya (Difco Laboratories, Detroit, Michigan, USA) con $0.25 \%$ de Dextrosa Anhidra (Mallinckrodt Baker Inc., Paris, Kentucky, USA); $3 \mathrm{ml}$ de este medio de cultivo fue adicionado a cada tubo; las muestras se incubaron durante 72 horas a $37^{\circ} \mathrm{C}$ para la verificación de los ciclos de esterilización de calor seco y a $57^{\circ} \mathrm{C}$ para los autoclaves, según lo establece la Farmacopea de los Estados Unidos Mexicanos, lo cual ha sido aceptado por otros investigadores de México. ${ }^{4,5}$ En cada muestra se utilizó un control positivo (crecimiento bacteriano), un control negativo (ausencia de crecimiento bacteriano) y un control del medio de cultivo. El procedimiento detecta crecimiento bacteriano o ausencia del mismo en los ciclos de esterilización; su presencia es considerada como un resultado positivo, y por lo tanto hay un mal funcionamiento del esterilizador; la ausencia de crecimiento bacteriano es considerada como resultado negativo y por lo tanto el equipo está funcionando adecuadamente. Los resultados fueron entregados por escrito a cada uno de los participantes. Se utilizó estadística descriptiva para las variables cualitativas y ji cuadrada para identificar posible asociación entre el crecimiento bacteriano (resultado positivo) y el método de esterilización; el programa estadístico utilizado fue Stat View (4.0).

\section{Resultados}

De los 200 CD que integran el CDP y la FE-UASLP, participaron 130 (65\%) en el estudio. De los $70(35 \%)$ que no participaron, $32 \mathrm{CD}$ no ejercen la profesión o no tienen consultorio dental; cinco no tienen esterilizador y esterilizan en alguna institución; seis sí tienen esterilizador, pero está descompuesto (no pueden realizar el ciclo de esterilización); 13 no participaron por falta de tiempo; 10 no entregaron el cuestionario contestado y a cuatro no se les pudo localizar. La consistencia interobservador para detectar la presencia o ausencia del crecimiento bacteriano fue de Kappa 0.90. En el cuadro I, se pueden observar los resultados de la verificación por IB; cada CD participó con un esterili- 
zador de calor seco o autoclave. Fueron 30 (23.0\%) autoclaves y $100(76.9 \%)$ esterilizadores de calor seco, de los cuales, $23(17.7 \%)$ resultaron positivos y $107(82.3 \%)$ negativos; de los 23 positivos, cuatro fueron autoclaves y 19 calor seco. Los dos métodos de esterilización empleados presentaron crecimiento bacteriano (resultados positivos) con frecuencia similar $\left(\chi^{2}=0.1941\right.$, $p=>0.6$ ). En los resultados de la encuesta a CD se encontró que de los 130 participantes, 95 (73.0\%) no utilizan ningún verificador, $14(10.7 \%)$ utilizan indicadores químicos, 21 (16.2\%) utilizan IB y 75 (57.6\%) no conocen los IB. A los CD que resultaron con una verificación positiva, se les analizó su cuestionario y se les hizo una segunda verificación para tratar de detectar las posibles causas de falla en los ciclos de esterilización, cuadro II. A los 23 equipos con resultado positivo se les modificó el tiempo, la temperatura, el precalentado; y en la segunda verificación resultaron negativos 21 (91.4\%). Sólo en dos (8.6\%) esterilizadores, uno de calor seco y un autoclave, a pesar de modificar el proceso de esterilización, no se les detectó la falla y el resultado de la verificación fue positiva. Ocho (6.1\%) CD contestaron correctamente el tiempo y temperatura en el proceso de esterilización, pero presentaron resultados positivos. Al analizar el cuestionario, observamos que el auxiliar realizaba el proceso de esterilización con temperaturas, tiempo y precalentado inadecuados.

\section{Discusión}

El control de infección en un consultorio debe ser un procedimiento de rutina, pues el personal relacionado con la salud está expuesto al contacto con microrganismos que producen enfermedades como el SIDA y

\section{Cuadro I \\ ReSUlTADOS DE LA VERIFICACIÓN CON INDICADORES BIOLÓGICOS DE ESTERILIZADORES DE CIRUJANOS dentistas. San Luis Potosi, México, 1999-2000}

\begin{tabular}{|c|c|c|c|c|c|c|}
\hline \multirow[b]{3}{*}{ Esterilizadores } & \multicolumn{4}{|c|}{ Crecimiento bacteriano } & \multirow{2}{*}{\multicolumn{2}{|c|}{ Total }} \\
\hline & \multicolumn{2}{|c|}{ Presencia } & \multicolumn{2}{|c|}{ Ausencia } & & \\
\hline & $\mathrm{n}$ & $\%$ & $n$ & $\%$ & $\mathrm{n}$ & $\%$ \\
\hline Autoclave & 4 & 13.3 & 26 & 86.7 & 30 & 100 \\
\hline Calor seco & 19 & 19.0 & 81 & 81.0 & 100 & 100 \\
\hline tal & 23 & 17.7 & 107 & 82.3 & 130 & 100 \\
\hline
\end{tabular}

$\mathrm{n}=$ número de esterilizadores $\chi^{2}=0.1941, p \geq 0.06$

\section{Cuadro II \\ MODIFICACIONES Y SEGUNDA VERIFICACIÓN \\ DE LOS ESTERILIZADORES QUE RESULTARON POSITIVOS CON INDICADORES BIOLÓGICOS. San Luis Potosí, México, 1999-2000}

$$
\frac{\text { Autoclave }}{n \%} \frac{\text { Calor seco }}{n \%} \text { Total }
$$

Modificaciones antes de la segunda

verificación

\begin{tabular}{lrrrrr} 
Tiempo y temperatura & 4 & 25 & 12 & 75 & 16 \\
\hline Precalentado & - & & 7 & 100 & 7
\end{tabular}

Segunda verificación con indicadores

biológicos

\begin{tabular}{lrrrrr} 
Ausencia de crecimiento bacteriano & 3 & 14 & 18 & 86 & 21 \\
\hline Crecimiento bacteriano & 1 & 50 & 1 & 50 & 2
\end{tabular}

la hepatitis B. ${ }^{6,7} \mathrm{La}$ ADA y la NOM desarrollaron lineamientos con el propósito de reducir el riesgo de transmisión de enfermedades en el consultorio dental (paciente-dentista o dentista-paciente), siendo uno de ellos, la desinfección y esterilización de instrumentos. ${ }^{1,2}$ La Norma Oficial Mexicana para la Prevención y Control de Enfermedades Bucales, establece en el artículo número 7.3.3.6 utilizar IB para el control de ciclos de esterilización del equipo usados por $\mathrm{CD}$, aplicándose una vez al mes. Existe esta exigencia a nivel nacional, pero aún no ha entrado en vigencia; la FE-UASLP usa IB mensualmente en todos los ciclos de esterilización realizados en sus equipos. ${ }^{2}$ En este estudio consideramos que las principales fallas respecto al crecimiento bacteriano se encuentran durante el proceso de esterilización por el tiempo, la temperatura y el precalentado inadecuados. Sólo en dos equipos no se pudo detectar la falla existente. Es recomendable realizar la primera verificación con IB desde la compra del equipo, ya sea nuevo o reconstruido. En un estudio piloto encontramos crecimiento bacteriano en dos equipos reconstruidos de origen extranjero. ${ }^{8}$ En relación con el uso de IB, en estudios hechos en México, queda de manifiesto que pocos $\mathrm{CD}$ emplean los IB. ${ }^{3,4}$ En nuestro estudio sólo $16.1 \%$ ( $\mathrm{n}=21$ ) los utilizan, por lo cual es importante informar acerca de los IB al gremio odontológico ya que es un método práctico, confiable y disponible en el mercado. ${ }^{3}$ Las conclusiones de nuestro estudio fueron las siguientes: a) pocos CD usan los IB para verificar los ciclos de esterilización; $b$ ) los errores 
del personal encargado de realizar el proceso de esterilización y las fallas mecánicas de los ciclos de esterilización se hacen evidentes con el uso de los IB.

\section{Referencias}

1. Molinari JA. Dental infection control at the year 2000.J Am D ent Assoc 1999;130:1291-1298.

2. N orma 0 ficial Mexicana para la Prevención y Control de Enfermedades Bucales. N O M-013-SSA 2-1994. Secretaría de Salud. Diario 0 ficial de la Federación, México, D.F.: 1 Enero 21,1999.

3. Parra LM,A costa E. Análisis de algunos indicadores biológicos disponibles comercialmente en México. Rev ADM 1999:56:151-154.
4. A guirre A, Sánchez TL, Acosta E.Verificación biológica de los ciclos de esterilización. Rev ADM 1999;56:234-237.

5. Secretaría de Salud. Farmacopea de los Estados U nidos Mexicanos. Sexta Edición. Métodos generales de análisis. México D.F.: SSA, 1994:165-172. 6. Maupome G,A costa E, Borges SA, Diez FJ. Survey on attitudes toward HIV infected individuals and infection control practices among dentists in México city.Am J Infect Control 2000;28:21-24.

7. Kershenobich D, Hurtado R, C ollawn C, Bobadilla J, C abrera G, Borovoy J et al. Seroprevalencia de marcadores virales de hepatitis $B$ en profesionales de la salud. Estudio multicéntrico en México. Rev Invest Clin1990;42:251-256.

8. Loyola JP, Patiño N, Solórzano JA, Santos MA. Verificación del funcionamiento de esterilización para uso odontológico en San Luis Potosí, México. Rev ADM 1998;55:277-282. 